\title{
Efficiency of methyl-esterified eggshell membrane biomaterials for intensified microalgae harvesting
}

\author{
Hee-Jeong Choi \\ Department of Energy and Environment Convergence, Catholic Kwandong University, Beomil-ro 579, Gangneung 25601, Republic of Korea
}

\begin{abstract}
This study investigates the use of methyl-esterified eggshell membranes (MESM) for the harvesting of microalgae species under various conditions. Eggshell membranes were esterified with $\mathrm{HCl}$ to impact polycationic characteristics. After methyl esterification, the negative surface charge property of eggshell membrane was changed from negative to positive for all $\mathrm{pH}$ values to improve microalgae sorption capacity. The harvesting efficiency of microalgae by MESM reached 78-99\% for all $\mathrm{pH}$ ranges evaluated. In addition, a 150 mesh particle size and $10 \mathrm{mg} \mathrm{L}^{-1} \mathrm{MESM}$ dose were found to yield up to $98 \%$ microalgae harvesting. These results indicate that the high cationic charge of MESM strongly adsorbs the negatively-charged microalgae. MESM is biocompatible and can be applied to the harvest of microalgae.
\end{abstract}

Keywords: Bio-adsorption, Eggshell, Harvesting, Methyl-esterified eggshell membrane (MESM), Microalgae

\section{Introduction}

Microalgae are attractive potential raw material for bioenergy because they do not require vast areas for cultivation, short growth period, high growth rate, and high lipid content compared with other plants biooil [1, 2]. Despite several advantages the harvesting of pure microalgae is expensive and required much energy. Especially, small size and low cell density of microalgae are harvested more costly [3]. According to the reports, the harvest of microalgae biomass accounted for $20-30 \%$ of total production costs $[3,4]$.

A number of techniques have been developed to harvest microalgae, such as flotation, filtration, centrifugation, adsorption and flocculation etc. From that, an adsorption and flocculation method is relatively simple and cost effective compared to other harvesting methods [5]. Flocculation has the advantage of high efficiency for microalgae harvesting. However, it requires a significant amount of chemical consumption. For example, typical flocculants include ferric and aluminum salt for flocculation of sample solutions greater than $600 \mathrm{mg} \mathrm{L}^{-1}$ of biomass [3, 6]. Moreover, the use of excess metals should be avoided since they may cause problems if the algae mass is to be used as a source for fuel production or as fish fodder, for instance [2]. Metals in oils extracted from biomass typically need to be removed before further processing [3, 7]. It is therefore necessary to develop a method that is equally efficient and vastly more economical to achieve a commercially adopted means of harvesting this material. The method utilizing methyl-esterified eggshell membrane (MESM) as an adsorbent for the harvesting of microalgae may be an alternative to adsorb algae present in an aqueous phase to effect rapid and gentle enrichment or concentration of algae.

The Korean food industry produces 90,000 tons of eggshell waste per year [3, 7]. The disposal uses for eggshell waste include $6.2 \%$ in fertilizer, $10.7 \%$ in animal feed ingredients, $3.2 \%$ in other applications, and the rest discarded as waste in Korea [3]. However, many landfills are reluctant to accept eggshell waste because the eggshells and the attached membrane attract pests $[8,9]$. The eggshell membrane (ESM) is located between the liquid white and the solid inner surface of the eggshell. The contents of $\mathrm{C}, \mathrm{H}, \mathrm{N}, \mathrm{O}$, and $\mathrm{S}$ in the ESM are $47.5 \%, 6.8 \%, 15.3 \%, 12.0 \%$, and $3.0 \%$, respectively [10]. Despite its porous structure, ESM is composed of a fibrous protein network. Therefore, ESM has good adsorbent properties, including the ability to remove heavy metal and dye from wastewater. In a previous study, ESM was shown to be positively charged at $\mathrm{pH}$ values of 1-6 and negatively charged at $\mathrm{pH}$ values of 6-12 [10, 11]. The surface property of the ESM dominates its sorption behaviors toward various ions and species. However, the negatively-charged carboxylic groups play an inhibitory role for
This is an Open Access article distributed under the terms of the Creative Commons Attribution Non-Commercial License (http://creativecommons.org/licenses/by-nc/3.0/) which permits unrestricted non-commercial use, distribution, and reproduction in any medium, provided the original work is properly cited.
Received June 15, 2016 Accepted April 16, 2017

${ }^{\dagger}$ Corresponding author

Email: hjchoi@cku.ac.kr

Tel: +82-33-649-7297 Fax: +82-33-647-7635

Copyright (C) 2017 Korean Society of Environmental Engineers 
adsorption of anion species by ESM [12, 13]. After methyl esterification, the ESM surface charge property is changed according to the esterification of carboxylic groups, which is the main driving force for the improvement of microalgae sorption capacity [10]. MESM has a high cationic charge density and can thus strongly adsorb and destabilize negative particles, such as negatively-charged microalgae cells. MESM from eggshell waste has been recommended for use as an adsorbent because of its low cost, copious availability, non-toxicity, high specific surface area, biodegradable, the high potential of ion exchange for charged pollutants, and safe handling [14, 15]. Many researchers have reported several biological, chemical, and physical processes for heavy metal removal using MESM [8, 10, 16, 17]. However, close examination of MESM for the harvesting of microalgae species has rarely been reported. Therefore, the novelty in this study is the proposal of an effective use of MESM for microalgae harvest in solution. We expect MESM to be used as an eco-friendly bio-sorbent instead of other chemical harvesting materials for microalgae.

\section{Materials and Methods}

\subsection{Microalgae Cultivation}

Chlorella vulgaris (C. vulgaris: KMMCC 145) was obtained from KMMCC (Korea Marine Microalgae Culture Center) and was cultivated in Jaworski's medium (JM) under LED (light-emitting diode) lamps at ambient temperature. The chemical composition of JM is given elsewhere [2,3]. The microalgae were cultured in a 200 $\mathrm{mL}$ conical flask containing $100 \mathrm{~mL} \mathrm{JM}$ with $10 \mathrm{~mL}$ C. vulgaris at $7.2 \pm 0.3$ of $\mathrm{pH}$. The cultures were maintained in a dark and light cycle of 8 and $16 \mathrm{~h}$, respectively, for 10 days. The temperature was maintained at $23^{\circ} \mathrm{C} \pm 1^{\circ} \mathrm{C}$ using LEDs. The LED light source was used because it is efficient and provides the required wavelength light from $430 \mathrm{~nm}$ to $670 \mathrm{~nm}$, which is selective for microalgal growth. Moreover, the light intensity was $200-250 \mu \mathrm{mol} \mathrm{m} \mathrm{m}^{-2}$. An equivalent $\mathrm{CO}_{2}$ aeration rate of $0.02 \mathrm{vvm}$ was used for cultivation. The initial concentration of the inoculated microalgae was 1.857 $\mathrm{g} \mathrm{L}^{-1} \pm 0.5 \mathrm{~g} \mathrm{~L}^{-1}$.

\subsection{Adsorbent}

Waste eggshell samples were collected from a chicken farm in Gangneung City, Korea. To remove all adhesion or interference materials, such as organics and salts, the sample was rinsed several times with deionized water and then boiled in water. After cleaning, eggshells were dried in an oven at $80^{\circ} \mathrm{C}$ for $24 \mathrm{~h}$. The dried eggshells were first pretreated with $15 \%(\mathrm{v} / \mathrm{v}) \mathrm{HCl}$ overnight to dissolve the outer layer of the shell and leave the ESM. The separated ESM was then cleaned using deionized water, dried at $80^{\circ} \mathrm{C}$ for $24 \mathrm{~h}$ in an oven, and crushed into fine powder using a mortar and pestle for future use. Next, $100 \mathrm{mg}$ of the pretreated ESM powder was immersed into $50 \mathrm{~mL}$ methanol containing $2 \%(\mathrm{v} / \mathrm{v}) \mathrm{HCl}$ for $10 \mathrm{~h}$ at $80^{\circ} \mathrm{C}$, during which process the carboxylic groups on the ESM structure were esterified [10]. The resultant MESM was rinsed several times with deionized water, dried at $80^{\circ} \mathrm{C}$ for $24 \mathrm{~h}$ in an oven, and stored in a desiccator for future use. Sorption by MESM should occur mainly through an exchange reaction, and it should be possible to use it as a new biological flocculent of microalgae.

\subsection{Methods}

The high cationic charge density of MESM allows it to strongly adsorb the negatively-charged regions of microalgae. Sorption by MESMs should occur mainly through an exchange reaction, and it should be possible to use MESM as a new biological harvesting method for microalgae. The experiment was carried out in the form of a batch-test. To determine the effect of microalgae harvesting, MESM doses ranging from 1 to $30 \mathrm{mg} \mathrm{L}^{-1}$ were added in the microalgae contained in $2 \mathrm{~L}$ water, and a MESM particle size of 20 to 320 mesh was used. The $\mathrm{pH}$ was controlled from 1 to 10 using $\mathrm{NaOH}$ and/or $\mathrm{H}_{2} \mathrm{SO}_{4}$, and the sample $\mathrm{pH}$ values tested ranged from 1 to 10 in single unit increments.

The mineralogy of the MESM and ESM was characterized by an X-ray diffractometer (Rikaku PMG-S2, 30 kV X 10 mA). Surface images of both MESM and ESM were obtained by a scanning electron microscope (SM-300, Topcon, Japan). The zeta potential of the MESM and ESM at different $\mathrm{pH}$ values was determined with a Malvern ZetaSizer Nano ZS90 (Malvern Instruments Ltd., UK). One milliliter of suspension was pipetted into a cuvette and inserted into the unit for determination of zeta potential and osmotic adjustment. Zeta potential was measured in triplicate at room temperature, and the average values were determined. MESM was sieved to obtain 0-320 mesh sizes using a mechanical sieve. The particle size and amount of sericite were analyzed using laser diffraction (Laser Diffraction Master Class 3 \& 4, Malvern, England) and micro-scales (XP26, Mettler Toledo, Swiss), respectively. The $\mathrm{pH}$ was measured using a $\mathrm{pH} / \mathrm{ORP}$ meter (ISTEK, $\mathrm{pH}-20 \mathrm{~N}$ ).

To determine the separation efficiency (SE), $10 \mathrm{~mL}$ of microalgae cells were placed in a $15 \mathrm{~mL}$ falcon tube. MESM and ESM were added at a designated concentration and mixed at $80 \mathrm{rpm} / \mathrm{min}$ using a mini orbital shaker (VWR Advanced Orbital Shaker, Model 15000). High-speed mixing tends to break the flocs, causing the adsorbed cells to be redisposed and reintroduced into the medium. After mixing, the algal cells were allowed to settle for $10 \mathrm{~min}$. Supernatant samples were collected over time from the middle of the algae suspension to obtain optical density (OD) measurements. The OD was measured at $680 \mathrm{~nm}$ (OD 680) by a spectrophotometer (Beckman Coulter, model DU 730) equipped with a carousel cell holder. The OD 680 values were calibrated against dry cell weight. The separation efficiency (\%) was calculated as follows:

$$
\text { Harvesting efficiency }(\%)=\left\{\left(\mathrm{OD}_{\mathrm{t} 0}-\mathrm{OD}_{\mathrm{t}}\right) / \mathrm{OD}_{\mathrm{t} 0}\right\} \times 100
$$

where $O D_{t o}$ is the optical density of samples taken at time zero ${ }_{\text {to) }}$, and $O D_{t}$ is the optical density at time $t$.

\subsection{Data Analysis}

Data presented in tables and figures represent mean values $\pm 3 \sigma$ of five replicates. Where error bars are not visible, errors were less than or equal to the symbols. The differences between mean values were calculated using Tukey's test at the 0.05 level by Origin software (v.7.5, OriginLab, Northampton, MA, USA). 


\section{Results and Discussion}

\subsection{Characterization of ESM and MESM}

Analyzed ESM and MESM surfaces are noted in Fig. 1. The ESM surface was positively charged at $\mathrm{pH}$ values of 1-6 and negatively charged at $\mathrm{pH}$ higher than 6 . These results suggested the negatively charged carboxyl group activated with increasing of $\mathrm{pH}$. When the negatively charged carboxyl group increased, the surface charge of ESM changed a significantly stronger negative charge. However, MESM was positively charged over the entire $\mathrm{pH}$ range. The potential of MESM was demonstrated as $5-10 \mathrm{mV}$ in all $\mathrm{pH}$ values, whereas that of ESM varied from 23.7 to $-16.2 \mathrm{mV}$ over all $\mathrm{pH}$ values and changed significantly at $\mathrm{pH}$. The negatively-charged carboxylic groups present on ESM should play an inhibitory role for adsorption of anion species [18]. After methyl esterification, the negative surface charge property of ESM is changed to positive for all $\mathrm{pH}$ values for improvement of microalgae sorption capacity. Variations in surface charge affect the interaction between particles and thus affect the adsorption efficiency. Adsorption using MESM is the result of particle collision and charge interaction between the charges of MESM and the microalgae surface in a liquid medium. In general the potential values of $\pm 5 \mathrm{mV}$ represent rapidly adsorption, which values from \pm 10 to $\pm 30 \mathrm{mV}$ represent instability adsorption, and values more than $\pm 30 \mathrm{mV}$ the particle is in stable and represent almost no adsorption due to the repulsive force between particles $[3,19]$. In this study, the MESM potential for all $\mathrm{pH}$ ranges was in the range of 0 to $8 \mathrm{mV}$. The apparent surface charge of the organic/inorganic matter is represented by its zeta potential, which might affect the adsorption efficiency.

Scanning electron microscopic (SEM) images of eggshell membrane samples before and after methyl esterification are shown in Figs. 2(a) and 2(b), respectively. The SEM images of ESM and MESM demonstrate similar morphologies. However after methyl esterification eggshell membrane intertwined like a thin thread and the specific surface area was expanded in order that adsorption of microalgae can better in aqueous solution. The energy dispersive spectroscopic (EDS) evaluation determined that the C, N, and S contents in ESM were 42.6\%, 31.5\%, and 9.9\%, respectively [20]. However, after methyl esterification, the contents of these elements

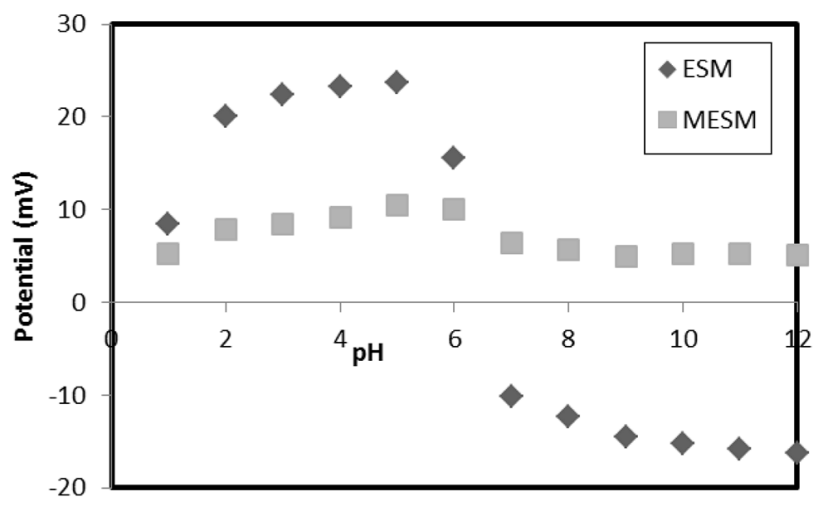

Fig. 1. Analysis of surface potential for ESM and MESM at different $\mathrm{pH}$ values (dosage of ESM: $10 \mathrm{mg} \mathrm{L}^{-1}$ and MESM: $10 \mathrm{mgL}^{-1}$ ).
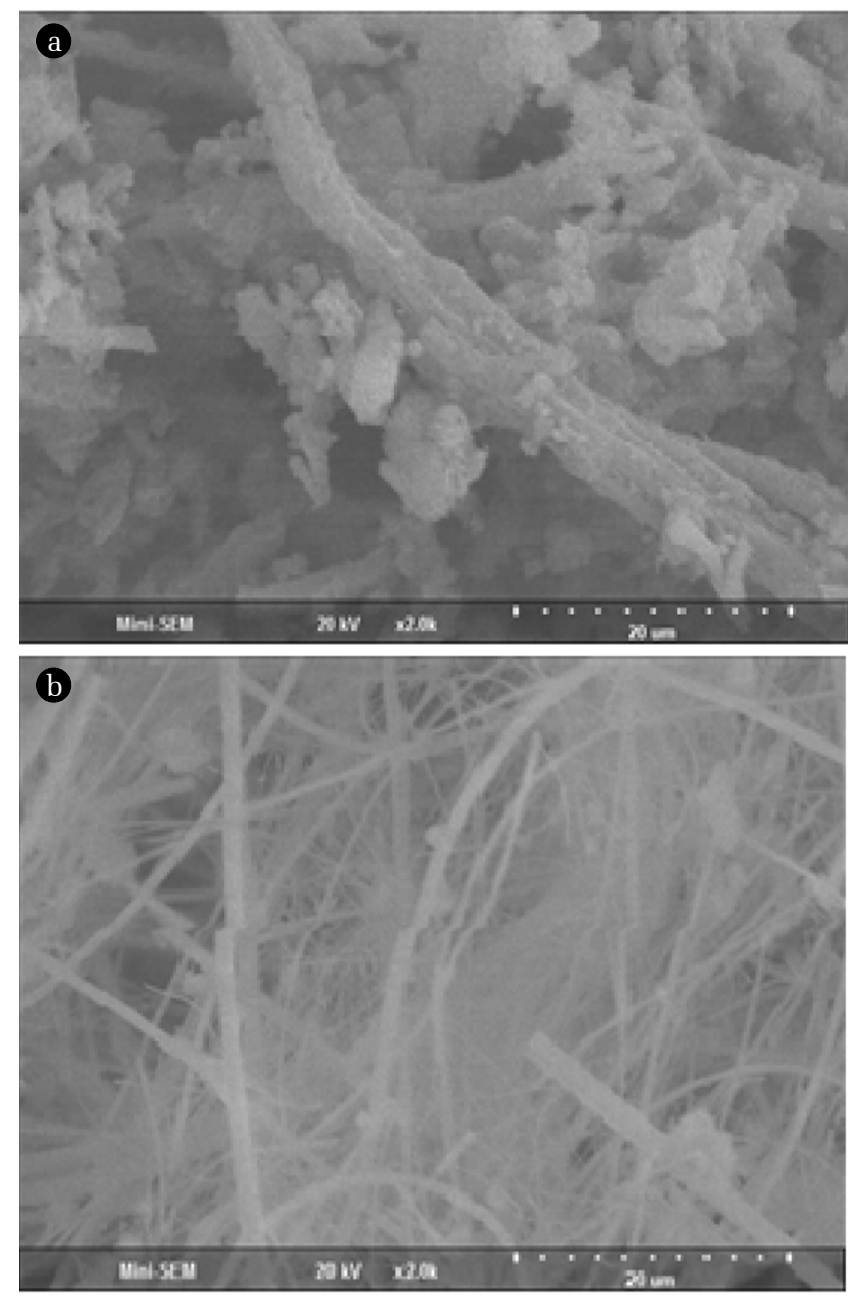

Fig. 2. SEM images of ESM (a) and MESM (b).

changed to $54.7 \%, 20.4 \%$, and $7.4 \%$, respectively. Chen et al. [10] reported that after the esterification process the presence of $-\mathrm{C}$ $=\mathrm{O}$ and $-\mathrm{C}-\mathrm{O}-\mathrm{C}$ bands, which are clear indicators of esterification, was confirmed with two new peaks $1,731 \mathrm{~cm}^{-1}$ and $1,187 \mathrm{~cm}^{-1}$. However, the major absorption bands for the ESM are still clearly observed after esterification, e.g., the absorption at $3,315 \mathrm{~cm}^{-1}$ assigned to the stretching vibration of hydroxyl groups, and the absorption $1,660 \mathrm{~cm}^{-1}$ attributed to the $-\mathrm{C}=\mathrm{O}$ stretching. The increase in $\mathrm{C}$ and decreases in $\mathrm{N}$ and $\mathrm{S}$ further indicated the esterification of carboxylic groups on the ESM surface. These changes show the negatively-charged ESM surface being changed to a positive surface after methyl esterification.

\subsection{Effect of $\mathrm{pH}$ on Microalgae Harvest}

The charge properties of the MESM and ESM surfaces and the microalgae species are closely related to sample $\mathrm{pH}$ (Fig. 3). Within the $\mathrm{pH}$ range of 1-6, the harvesting efficiency of microalgae was $<77 \%$ for ESM; however, the adsorption efficiency by ESM was negligible within the entire $\mathrm{pH}$ range studied, i.e., $\mathrm{pH}$ 7-12. These trends are associated with zeta potential. By analyzing the ESM surface, we confirmed it was positively charged at $\mathrm{pH}$ values 1-6 


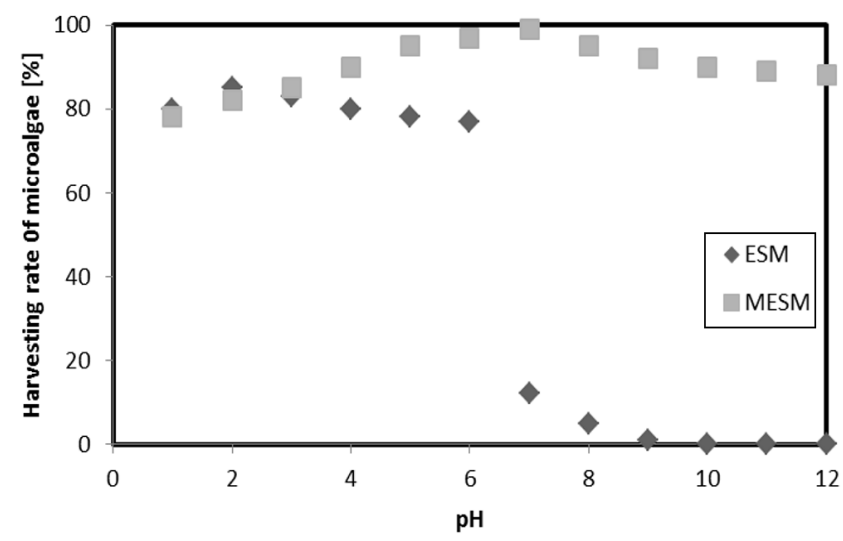

Fig. 3. Harvesting efficiency of microalgae at different $\mathrm{pH}$ values (MESM $10 \mathrm{mg} \mathrm{L}^{-1}$, concentration of microalgae $1.857 \mathrm{~g} \mathrm{~L}^{-1}$, and particle size of MESM 150 mesh).

and negatively charged at $\mathrm{pH} 7$ or greater (Fig. 1). The negatively-charged ESM should play an inhibitory role on the adsorption of negative microalgae. In contrast, the harvesting efficiency of microalgae by MESM reached 78-99\% in all $\mathrm{pH}$ ranges. After methyl esterification, the negative surface charge of ESM was changed to positive for all $\mathrm{pH}$ values, demonstrating improvement of sorption capacity toward negatively-charged microalgae. Therefore, an effective harvesting efficiency by MESM was obtained for all $\mathrm{pH}$ values. The maximum harvesting efficiency of $99 \%$ by MESM was recorded at $\mathrm{pH}$ 7. Therefore the best $\mathrm{pH}$ for harvesting of microalgae recommended $\mathrm{pH} 7$.

\subsection{Effect of MESM Dosage on Microalgae Harvesting}

The effect of MESM dosage on microalgae harvesting is depicted in Fig. 4. The harvesting efficiency of microalgae was $<30 \%$ with $5 \mathrm{mg} \mathrm{L}^{-1}$ of MESM and $>99 \%$ at up to $10 \mathrm{mg} \mathrm{L}^{-1}$ of MESM at $\mathrm{pH}$ 7. At up to $10 \mathrm{mg} \mathrm{L}^{-1}$ of MESM, the harvesting efficiency of microalgae was not changed and showed nearly complete harvest. The microalgae concentration also decreased significantly until $10 \mathrm{mg} \mathrm{L}^{-1} \mathrm{MESM}$ according to increasing MESM dosage. A large adsorbent surface is very important for microalgae adsorption.

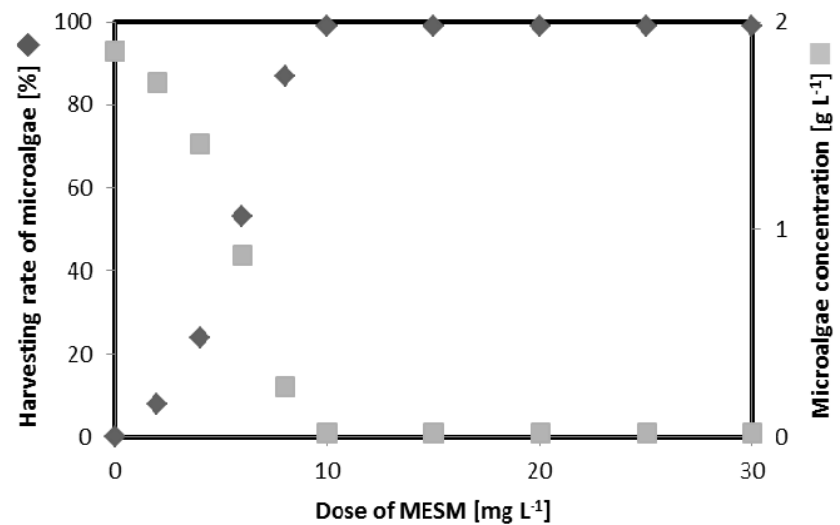

Fig. 4. Harvesting efficiency of microalgae by different MESM amount $(\mathrm{pH} 7)$.

\subsection{Effect of Particle Size on Microalgae Harvesting}

A smaller particle size is better for adsorption of materials, because the total surface of smaller particles is greater than that of larger particles. Accordingly, the adsorption capacity increased with small particles compared with larger particles. The harvesting efficiencies of microalgae by various MESM particle sizes are noted in Fig. 5. The maximum microalgae harvesting efficiency was observed as $56-70 \%$ with $20-80$ mesh, $90-97 \%$ with $120-140$ mesh, and greater than $98 \%$ with a MESM particle size > 150 mesh. The harvesting efficiency of microalgae depends on the particle size; however, up to 150 mesh, MESM showed similar results. Therefore, the optimum MESM particle size for harvesting is suggested as 150 mesh. Moreover, the MESM surface provides active sites that are capable of adsorbing microalgae from aqueous solutions, and this ability is further enhanced under elevated solution $\mathrm{pH}$ conditions [18]. Adsorption using MESM is a consequence of its surface energy being similar to its surface tension. Before equilibrium is reached between the MESM and microalgae, the harvesting efficiency increased with increasing surface area at a constant $10 \mathrm{mg} / \mathrm{L} \mathrm{MESM.}$ However, if equilibrium is reached between MESM and microalgae, then the adsorption force is weak. After equilibrium, the microalgae sorption by MESM was not changed significantly, thereby further increasing the importance of particle size and dosage. This may be due to the fact that the MESM surface area of the $>150$ mesh particle size was not significantly changed compared with that of the $<150$ mesh particle size.

Equilibrium modeling was studied for adsorption of microalgae onto MESM. The results obtained using the Langmuir and Freundlich isotherm models are represented in Table 1. The Langmuir isotherm provides a better fit than the Freundlich isotherm. The maximum adsorption capacity of MESM was 59.6 $\mathrm{mg} \mathrm{g}^{-1}$ according to the Langmuir isotherm.

Microalgae are taken up by MESM through adsorption. The microalgae are quickly adsorbed over the MESM surface; this process is called physical adsorption. In the present investigation, by decreasing the particle size, the percentage of harvested microalgae slowed gradually, and an apparent equilibrium was established. Upon reaching equilibrium, the microalgae sorption by MESM was not changed significantly, despite further increases in the dosage

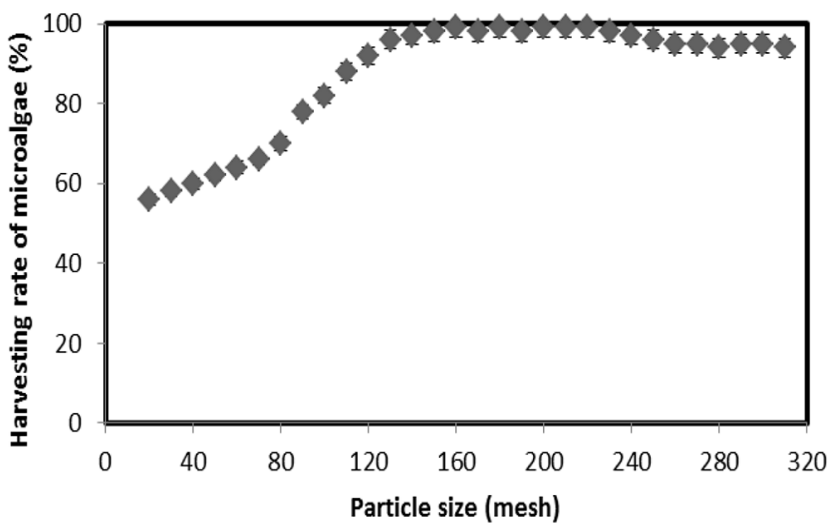

Fig. 5. MESM particle size affects on microalgae harvesting efficiency ( $\mathrm{pH} 7$ and $10 \mathrm{mg} \mathrm{L}^{-1}$ dosage). 
Table 1. Isotherm Equations for Microalgae Adsorption onto MESM

\begin{tabular}{ccl}
\hline \multicolumn{1}{c}{ Model } & \multicolumn{1}{c}{ Equation } & \multicolumn{1}{c}{ Parameters } \\
\hline Langmuir & $1 / \mathrm{q}_{\mathrm{e}}=1 /\left(\mathrm{q}_{\mathrm{m}} \times \mathrm{K}_{\mathrm{L}}\right) \times\left(1 / \mathrm{C}_{\mathrm{e}}\right)+1 / \mathrm{q}_{\mathrm{m}}$ & $\mathrm{q}_{\mathrm{m}}\left(\mathrm{mg} \mathrm{g}^{-1}\right)=59.6$ \\
& & $\mathrm{~K}_{\mathrm{L}}=0.004$ \\
& & $\mathrm{R}^{2}=0.9934$ \\
& & $\mathrm{SSR}=0.11$ \\
\hline Freundlich & $\ln \left(\mathrm{q}_{\mathrm{e}}\right)=\ln \left(\mathrm{K}_{\mathrm{F}}\right)+1 / \mathrm{n} \ln \left(\mathrm{C}_{\mathrm{e}}\right)$ & $\mathrm{n}=1.1$ \\
& & $\mathrm{~K}_{\mathrm{F}}\left(\mathrm{mg} \mathrm{g}^{-1}\right)=0.6$ \\
& & $\mathrm{R}^{2}=0.9812$ \\
& & $\mathrm{SSR}=0.09$ \\
\hline
\end{tabular}

$\mathrm{q}_{\mathrm{e}}$ : Amount adsorbed at equilibrium $\left(\mathrm{mg} \mathrm{g}^{-1}\right), \mathrm{C}_{\mathrm{e}}$ : Equilibrium concentration (mg L $\left.{ }^{-1}\right), \mathrm{q}_{\mathrm{m}}$ : Adsorption capacity $\left(\mathrm{mg} \mathrm{g}^{-1}\right), \mathrm{K}_{\mathrm{L}}\left(\mathrm{L} \mathrm{mg}^{-1}\right)$ : Langmuir constant, $\mathrm{K}_{\mathrm{F}}\left(\mathrm{L} \mathrm{mg}^{-1}\right)$ : Freundlich constant, n: Freundlich constant, SSR: Sum of Squared Residuals

and operation time. MESM is an excellent biosorbent due to pore structure and protein acid mucopolysaccharide contents. ESM has been used by many researchers for the adsorption and immobilization of several metal and inorganic ions to prevent their hazardous impacts on humanity and the environment as a whole $[17,21,22]$.

\subsection{Microalgae Concentration and Dose of MESM}

The relationship of microalgae concentration and MESM is represented in Fig. 6. The relation coefficient $\left(\mathrm{R}^{2}\right)$ of microalgae concentration and MESM dosage was determined as 0.9812. Increasing microalgae concentration increased the required amount of MESM. In the experiment, the 2.3-2.5 $\mathrm{mg} \mathrm{L}^{-1}$ of MESM adsorbed approximately $1 \mathrm{~g} \mathrm{~L}^{-1}$ microalgae. MESM is a very effective bio adsorption material for microalgae harvesting. The adsorption capacity of MESM is superior due to higher contents of carbonate groups. The effects of process parameters such as $\mathrm{pH}$, microalgae concentration, amount of adsorbent, and adsorbent pore size on process equilibrium showed that the uptake of microalgae by MESM was increased by increasing the microalgae concentration and adsorbent dosage and decreased by increasing the adsorbent size.

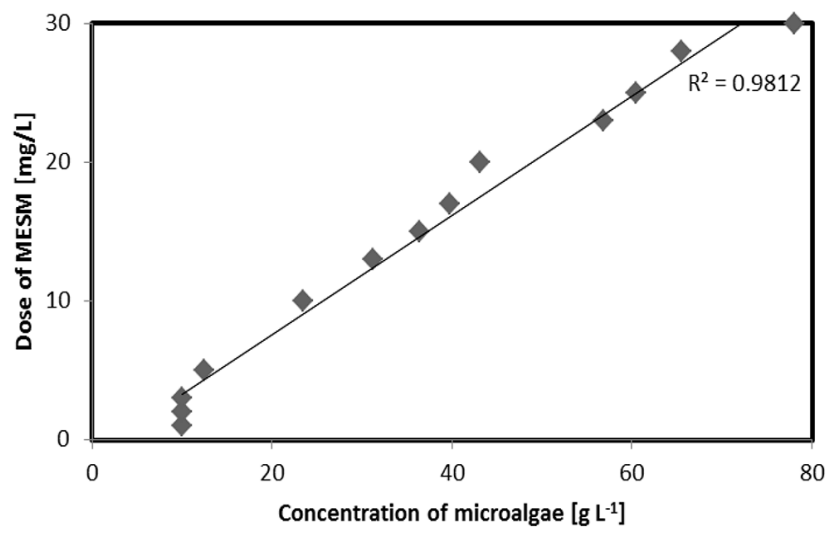

Fig. 6. Relationship of MESM dose and microalgae concentration $(\mathrm{pH}$ 7, particle size of MESM 150 mesh and > 99\% harvesting rate of microalgae).

\subsection{Desorption and Reusability}

It is necessary to find a suitable eluent which allows the reusability of the adsorbents. In this study, $\mathrm{NaOH}$ is found to be a suitable eluent compared with $\mathrm{HCl}$ and the percentage of microalge desorbed using various concentration of $\mathrm{NaOH}$ or $\mathrm{HCl}$ is given in Fig. 7(a). It is observed that $0.05 \mathrm{~mol} / \mathrm{L} \mathrm{NaOH}$ could desorb $90.75 \%$ of microalgae within $2 \mathrm{~h}$ contact. The percentage of desorption with $\mathrm{HCl}$ was obtained lower than using $\mathrm{NaOH}$ and it desorb $69.95 \%$ of microalgae by $0.05 \mathrm{~mol} / \mathrm{L} \mathrm{HCl}$. Although $\sim 92.75 \%$ by $0.2 \mathrm{~mol} / \mathrm{L}$ $\mathrm{NaOH}$ and $\sim 70.92 \%$ by $0.2 \mathrm{~mol} / \mathrm{L} \mathrm{HCl}$ for microalgae, further increase in $\mathrm{NaOH}$ and $\mathrm{HCl}$ concentration above $0.05 \mathrm{~mol} / \mathrm{L}$ did not significant increase in desorption of microalgae. Therefore, $0.05 \mathrm{~mol} \mathrm{NaOH}$ solution was recommend for regeneration of MESM. The desorption with $\mathrm{NaOH}$ was higher than that of $\mathrm{HCl}$. This suggests that an increase in the $\mathrm{OH}^{-}$ion in the aqueous solution with a higher concentration of $\mathrm{NaOH}$ increased the repulsion between the $\mathrm{OH}^{-}$ion and the microalgae. Thus, desorption of MESM was increased with increasing of $\mathrm{NaOH}$ concentration. Furthermore, reusability of MESM with $0.05 \mathrm{~mol} \mathrm{NaOH}$ for adsorption of microalgae was studied and results were shown in Fig. 7(b). The adsorption of microalgae was decreased as the number of adsorption-desorption cycles increased; however, $\mathrm{Ca} 62 \%$ of microalgae was adsorbed even after the material passed through five replicates of adsorption-desorption cycles. Therefore, this
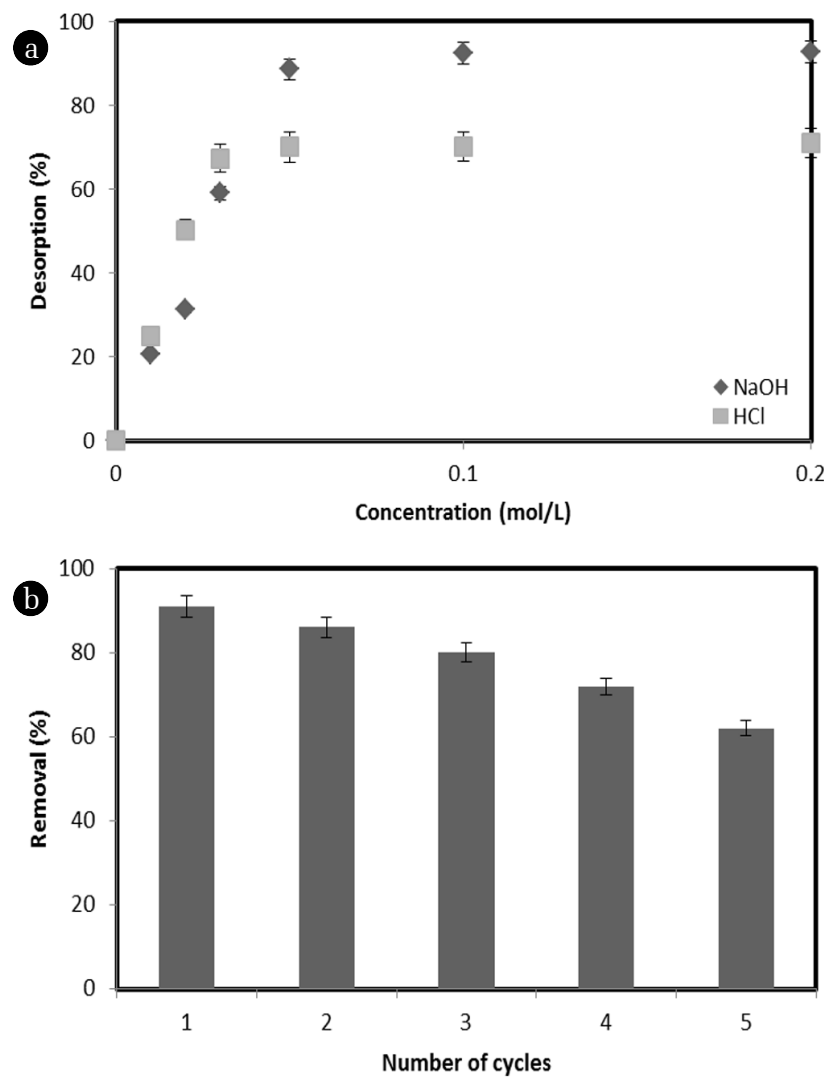

Fig. 7. Desorption of microalgae from MESM using $\mathrm{NaOH}$ and $\mathrm{HCl}$ (a) percentage removal of microalgae in sequential adsorption-desorption cycles (b). 
study indicates that the MESM is a suitable and excellent material for multiple uses in the adsorption of microalgae simultaneously from aqueous solution.

In the present research, the esterification of carboxylic groups on ESM with methanol was investigated to harvest microalgae. The high cationic charge density of MESM allows it to strongly adsorb negative particles. The mechanism of microalgae binding by activated MESM may depend on the $\mathrm{pH}$, microalgae concentration, dose, and MESM particle size. MESM is an abundant, low-cost material and has valuable applications in chemistry and chemical technology. It has attractive adsorption properties; additionally, it can be regenerated by a number of applications. The main component of MESM is protein, which contains amines and carboxylic groups, as well as fiber and a small amount of polysaccharide [23, 24]. Therefore, the harvested microalgae using MESM is applicable for use in biodiesel, animal feed, food, and medicine. In the business world cost is very important. Organic flocculants such as cationic polyacrylamide, cationic starch, and chitosan are biodegradable and offer low toxicity [25] but have high prices i.e., $\$ 10$ to 100 USD per kilogram for chitosan $[5,26]$ and $\$ 5$ to 30 USD per kilogram for cationic starch [6]. In contrast, MESM is inexpensive ( $\$ 0.1$ to 0.5 USD) and represents a reuse of waste. This harvesting method helps reduce the production cost of algae for biodiesel.

\section{Conclusions}

This study investigated the harvesting of microalgae using MESM. The negatively-charged ESM can play an inhibitory role for the adsorption of negatively-charged microalgae. In contrast, the harvesting efficiency of microalgae by MESM reached 78-99\% for all $\mathrm{pH}$ values tested. After methyl esterification, the negative surface charge property of ESM was changed to positive, thereby improving sorption capacity toward the negatively-charged surface of microalgae. Therefore, the harvesting efficiency obtained by MESM was highly effective for all $\mathrm{pH}$ values. The maximum harvesting efficiency of $99 \%$ by MESM was recorded at $\mathrm{pH} 7$. A harvesting efficiency $<30 \%$ was obtained within $5 \mathrm{mg} \mathrm{L}^{-1}$ of MESM, and that $>99 \%$ was noted at up to $10 \mathrm{mg} \mathrm{L}^{-1}$ of MESM at $\mathrm{pH}$ 7. Microalgae concentration decreased within increasing MESM dosage, as the MESM surface area also increased. The maximum microalgae harvesting efficiency was observed as $56 \%$ - 70\% for $20-80$ mesh, $90 \%$ - 97\% for $120-140$ mesh, and greater than $98 \%$ for $>150$ mesh MESM particle size. After the equilibrium period, the microalgae sorption by MESM was not changed significantly, despite further increases in particle size and dosage. The maximum adsorption capacity of MESM was $59.6 \mathrm{mg} \mathrm{g}^{-1}$ according to the Langmuir isotherm. In the experiment, 2.3-2.5 $\mathrm{mg} \mathrm{L}^{-1} \mathrm{MESM}$ absorbed approximately $1 \mathrm{~g} \mathrm{~L}^{-1}$ microalgae. Thus, MESM is a highly effective bio-adsorbent material for microalgae harvesting.

\section{Acknowledgments}

This study was supported by the Basic Science Research Program through the National Research Foundation of Korea (NRF) funded by the Ministry of Education, Science, and Technology (2016005271).

\section{References}

1. Choi HJ. Effect of optical panel distance in a photobioreactor for nutrient removal and cultivation of microalgae. World J. Microbiol. Biotechnol. 2014;30:2015-2023.

2. Lee SM, Choi HJ. Harvesting of microalgae species using Mg-Sericite flocculant. Biopro. Biosys. Eng. 2015;38:2323-2330.

3. Choi HJ. Effect of eggshells for the harvesting of microalgae species. Biotechnol. Biotec. Eq. 2015;29:666-672.

4. Gupta PL, Lee SM, Choi HJ. A mini review: Photobioreactors for large scale algal cultivation. World J. Microbiol. Biotechnol. 2015;31:1409-1417.

5. Xu Y, Purton S, Baganz F. Chitosan flocculation to aid the harvesting of the microalga Chlorella sorokiniana. Bioresour. Technol. 2013;129:296-301.

6. Papazi A, Makridis P, Divanach P. Harvesting Chlorella minutissima using cell coagulants. J. Appl. Phycol. 2010;2:349-355.

7. Choi HJ, Lee SM. Heavy metal removal from acid mine drainage by calcined eggshell and microalgae hybrid system. Environ. Sci. Pollunt. Res. 2015;22:13404-13411.

8. Liu N, Liu Y, Luan Y, Hu X. The elimination of heavy metal-containing wastewater by eggshells membrane. Appl. Mech. Mater. 2013;299:207-210.

9. Tsai WT, Hsien KJ, Hsu HC, Lin CM, Lin KY, Chiu CH. Utilization of ground eggshell waste as an adsorbent for the removal of dyes from aqueous solution. Bioresour. Technol. 2008;99:1623-1629.

10. Chen ML, Gu CB, Yang T, Sun Y, Wang JH. A green sorbent of esterified egg-shell membrane for highly selective uptake of arsenate and speciation of inorganic arsenic. Talanta 2013;116:688-694.

11. Baláž M. Eggshell membrane biomaterial as a platform for applications in materials science. Acta Biomater. 2014;10:3827-3843.

12. King'ori AM. A review of the uses of poultry eggshells and shell membranes. Int. J. Poult. Sci. 2011;10:908-912.

13. Chen H, Liu J, Cheng X, Peng Y. Adsorption for the removal of malachite green by using eggshell membrane in environment water samples. Adv. Mater. Res. 2012;573-754:63-67.

14. Torres FG, Troncoso OP, Piaggio F, Hijar A. Structure-property relationships of a biopolymer network: The eggshell membrane. Acta Biomater. 2010;6:3687-3693.

15. Zhang RH, Yang XL, Liu J, Cheng XZ. Eggshell membrane biomaterials for adsorption and determination of $\mathrm{Mn}(\mathrm{II}, \mathrm{VII})$ in environmental water. Adv. Mater. Res. 2012;457-458: 536-539.

16. Zhao YH, Chi YJ. Characterization of collagen from eggshell membrane. Biotechnology 2009;8:254-258.

17. Pettinato M, Chakraborty S, Arafat HA, Calabro V. Eggshell: A green adsorbent for heavy metal removal in an MBR system. Ecotoxicol. Environ. Safe. 2015;121:57-62.

18. Tsai WT, Yang JM, Lai CW, Cheng YH, Lin CC, Yeh CW. Characterization and adsorption properties of eggshells and eggshell membrane. Bioresour. Technol. 2006;97:488-493. 
19. Choi HJ. Effect of Mg-sericite flocculant for treatment of brewery wastewater. Appl. Clay Sci. 2015;11:145-149.

20. Nakano T, Ikawa NI, Ozimek L. Chemical composition of chicken eggshell and shell membranes. Pollut. Sci. 2003;82:510-514.

21. Guru PS, Dash S. Sorption on eggshell waste - A review on ultrastructure, biomineralization and other applications. $A d v$. Colloid Interface Sci. 2014;209:49-67.

22. D'Souza SF, Kumar J, Jha SK, Kubal BS. Immobilization of the urease on eggshell membrane and its application in biosensor. Mater. Sci. Eng. 2013;C33:850-854.

23. Baláž M, Zorkovská A, Fabián M, Girman V, Briancin J. Eggshell biomaterial: Characterization of nanophase and polymorphs after mechanical activation. Adv. Powder Technol. 2015;26: 1597-1608.

24. Ponkham W, Limroongreungrat K, Sangnark A. Extraction of collagen from hen eggshell membrane by using organic acids. Thai J. Agr. Sci. 2011;44:354-360.

25. Pragya N, Pandey KK, Sahoo PK. A review on harvesting, oil extraction and biofuels production technologies from microalgae. Renew. Sust. Energ. Rev. 2013;24:159-171.

26. Lee YC, Kim B, Farooq W, et al. Harvesting of oleaginous Chlorella sp. by organoclays. Bioresour. Technol. 2013b;132: 440-445. 